\title{
Simultaneous Use of Two Different Tools to Assess Compliance with Antiepileptic Drugs: Experience in A Community-Based Study
}

\author{
Paramjit Singh ${ }^{1} \quad$ Kanchan Gupta ${ }^{1}$ Gagandeep Singh ${ }^{2}$ Sandeep Kaushal ${ }^{1}$ \\ 1Department of Pharmacology, Dayanand Medical College and \\ Hospital, Ludhiana, Punjab, India \\ 2Department of Neurology, Dayanand Medical College and \\ Hospital, Ludhiana, Punjab, India \\ Address for correspondence Paramjit Singh, MBBS, \\ 933, Block-G, SBS Nagar, Ludhiana 141001, Punjab, India \\ (e-mail: Paramjit.296@gmail.com).
}

J Neurosci Rural Pract 2020;11:636-639

\begin{abstract}
Objective Antiepileptic drug (AED) therapy remains the primary form of treatment for epilepsy, noncompliance to which can result in breakthrough seizure, emergency department visits, fractures, head injuries, and increased mortality. Various tools like self-report measures, pill-counts, medication refills, and frequency of seizures can assess compliance with varying extent. Thus, assessment of compliance with AEDs is crucial to be studied.

Materials and Methods Compliance was assessed using pill-count and Morisky medication adherence scale (MMAS) during home visits. A pill-count (pills dispensedpills remaining)/(pills to be consumed between two visits) value of 0.85 to $\leq 1.15$ was recorded as appropriate compliance. Underdose $(<0.85)$ and overdose $(>1.15)$ was labeled as noncompliance. Score of 1 was given to each positive answer in MMAS. Score of $\geq 1$ was labeled as noncompliance.

Statistical analysis: Relationship of demographic factors between compliant and noncompliant patients was analyzed using Chi-square test (SPSS version 21.0, IBM). Rest of the data was analyzed with the help of descriptive statistics using Microsoft Excel. $p<0.05$ was considered statistically significant.

Keywords

- Compliance

- Anti-epileptic drugs

- MMAS

- Pill-count

Results Out of 105 patients, 54 patients were noncompliant with both pill-count and MMAS. 10 patients were noncompliant with pill-count only, while 10 were noncompliant with MMAS.

Conclusion Both tools complement each other when used in combination, as use of a single tool was not able to completely detect compliance.
\end{abstract}

\section{Introduction}

Epilepsy is a condition in which a person has recurrent episodes of seizures due to a chronic, underlying process. ${ }^{1}$ Antiepileptic drug (AED) therapy remains the principal treatment for epilepsy, which is often prescribed for a long duration. Treatment with AEDs helps in controlling seizures and substantially impacts quality of life in patients with epilepsy (PWE). ${ }^{2}$ Although AEDs may not cure the condition, but PWE may remain seizure-free and thus have a better quality of life, if they follow an appropriate AED-regimen.

The extent to which behavior of a patient matches with prescriber's advice is defined as compliance. ${ }^{3}$ Compliance to AEDs is crucial in preventing or minimizing seizure, as noncompliance to AEDs can result in break through seizures, emergency department visits, hospitalizations, fractures, head injuries, and increased mortality. ${ }^{4}$ Noncompliance to medication is a prevalent and persistent healthcare problem, 
particularly for people with a chronic disorders like epilepsy. Noncompliance to prescribed AED regimen is shown in approximately 21 to $42 \%$ of patients. ${ }^{5}$

Methods to evaluate compliance can be divided into direct methods like measuring levels of drug in blood or observing patients taking drug and indirect methods like reporting through self-reported questionnaires and patient diaries, pill-counting, and electronic drug monitoring. Each method has different benefits over each other. Some methods can only explore the consumption of medication over a period of time but cannot explain how a particular regime was followed. ${ }^{6}$ Self-report questionnaires like Morisky medication adherence scale (MMAS) are commonly used to study compliance with AEDs in epilepsy. ${ }^{7}$ Although these methods are easily adaptable and noninvasive to target population, they might over report compliance due to a tendency to give a socially desirable response. ${ }^{8}$ After self-report measures, the second most common noninvasive method is pill-counting. ${ }^{7}$ This method is documented to a smaller extent in literature but might have been used more frequently. Number of pills can be easily altered by patients outside a controlled environment. Hence, we planned to combine these two tools to study their usefulness to assess compliance.

\section{Materials and Methods}

This was a prospective observational study conducted among PWE in a community in the Ludhiana city of Punjab state after taking prior approval from institutional ethics committee.

Ludhiana city was divided into small clusters, which were prepared according to geographic information system (GIS) data. Among the identified clusters, PWE were approached to participate in the study. Diagnosis was confirmed by arranging a consultation with a neurologist (EEG and neuroimaging were done wherever applicable). Those who consented were included after taking a written informed consent in their vernacular language, that is, Hindi/Punjabi. Patients who were on AED therapy, aged $\geq 18$ years, of either gender, with any comorbid condition and belonging to any socioeconomic status were included in the study. Patients with nonepileptic seizures and those not consenting to participate were excluded from the study. Monthly follow-up was done for a period of 6 months to record compliance with AEDs. PS made personal visits to the households and collected data on a semistructured proforma.

Pill count and MMAS were two different tools used to assess compliance during home visits. Pill count was calculated using the following formula:Pills dispensed-pills remaining)/number of tablets to be consumed between two visits. A pill-count value of 0.85 to $\leq 1.15$ was recorded as appropriate compliance to prescribed regimen. Value $<0.85$ was recorded as underdose and $>1.15$ was recorded as overdose of prescribed AED regimen. Overdose or underdose of prescribed regimen was labeled as noncompliance.

MMAS was administered to each patient during each home visit. Score of 1 was given to each positive answer and 0 for negative answer, thus giving a range of 0 to 4 scores for each patient. Patients with score $\geq 1$ were labeled as noncompliant. Forgetfulness and carelessness about prescribed regimen were recorded as nonintentional cause of noncompliance. Change in prescribed regimen because of feeling better or getting worse with treatment was recorded as intentional noncompliance behavior.

The data obtained in study was subjected to statistical analysis with Microsoft Excel for Mac 2011 (version 14.0.0 [100825]) and SPSS (version 21.0, IBM).

\section{Results}

Out of 115 patients enrolled in the study, seven patients withdrew their consent to participate and three patients shifted to another city. Complete analysis was performed in 105 patients.

The mean age of patients was $33.6 \pm 13.6$ years and mean weight was $58.6 \pm 14.7 \mathrm{~kg}$. Demographic distribution of enrolled patients is given in - Table1. Family history of epilepsy was present in 31 (29.5\%) patients. Maximum number of patients ( $n=67,63.8 \%$ ) were diagnosed with idiopathic generalized epilepsy (IGE), followed by temporal lobe epilepsy ( $n=12,11.4 \%)$ and IGE with juvenile myoclonic epilepsy in 5 (4.8\%). Generalized tonic clonic seizures (GTCS) was maximum reported seizure semiology among patients $(n=96,91.4 \%)$.

Noncompliance was higher for all AEDs when used in polytherapy as compared with monotherapy. Majority of noncompliant patients were receiving sodium valproate, followed by phenobarbitone and carbamazepine.

Table 1 Demographic characteristics of the study population

\begin{tabular}{|c|c|c|}
\hline Characteristic & $\begin{array}{l}\text { Total. } \\
(n)\end{array}$ & $\begin{array}{l}\text { Percentage } \\
(\%)\end{array}$ \\
\hline \multicolumn{3}{|l|}{ Age group } \\
\hline $18-40$ years & 77 & 73.3 \\
\hline $41-60$ years & 22 & 21.0 \\
\hline$>60$ years & 6 & 5.7 \\
\hline Total & 105 & 100.0 \\
\hline \multicolumn{3}{|l|}{ Gender } \\
\hline Female & 41 & 39.0 \\
\hline Male & 64 & 61.0 \\
\hline Total & 105 & 100.0 \\
\hline \multicolumn{3}{|l|}{ Residential area } \\
\hline Rural & 12 & 11.4 \\
\hline Urban & 93 & 88.6 \\
\hline Total & 105 & 100.0 \\
\hline \multicolumn{3}{|c|}{ Socioeconomic status } \\
\hline Lower & 8 & 7.6 \\
\hline Upper lower & 41 & 39.0 \\
\hline Lower middle & 33 & 31.4 \\
\hline Upper middle & 21 & 20.0 \\
\hline Upper & 2 & 2.0 \\
\hline Total & 105 & 100.0 \\
\hline
\end{tabular}


Over a period of 6 months, an equal number of patients was found to be noncompliant with both pill-count and MMAS ( $n=64)$. After comparison of data from pill-count and MMAS, a significant difference between noncompliant patients was found ( $p=0.000$; - Table 2 ).

\section{Discussion}

The acceptable level of patient compliance in medical practice is different, according to various reports and the disease being treated. For PWE, compliance to drug treatment is very critical, as approximately $50 \%$ of patients become seizure-free with the first drug endeavored ${ }^{6}$. Approximately, 21 to $42 \%$ of PWE show nonadherence to prescribed AEDs regimen for epilepsy management. ${ }^{8}$ The present study provides the insights into the current trend of compliance to AEDs in community, and influence of simultaneous use of two different tools to assess non-compliance.

Most of the noncompliant patients in our study belonged to the 18 to 40 -year age group ( $n=77,73.3 \%$ ). In a cross-sectional study conducted by Gurumurthy et al, a similar pattern was seen. ${ }^{9}$

In our study, noncompliance was higher for all AEDs when used in polytherapy as compared with monotherapy. Majority of noncompliant patients were receiving sodium valproate, followed by phenobarbitone and carbamazepine. This is in accordance with the view that both sodium valproate and phenobarbitone are most commonly used as polytherapy. Similar results were shown in study conducted by Habib et al. ${ }^{10}$ Drowsiness is frequent adverse effect with carbamazepine,which can lead to noncompliance.

To the best of our knowledge, simultaneous use of pill-count with self-reported questionnaire like MMAS has not been seen frequently in assessment of compliance with AEDs, although both tools have been used separately in various studies. We found in this study that noncompliance with AEDs is common among PWE. The total number of noncompliant patients assessed with pill-count and MMAS were 64 (61\%), of which 54 (51.4\%) patients were noncompliant with both pill-count and MMAS, and 10 patients reported noncompliance with only one of the two tools, that is, either pill-count or MMAS. In another similar study conducted by Johnbull et al, only $32.6 \%$ patients were found compliant to the prescribed AED regimen. ${ }^{11}$

In our study, 10 patients, who were found noncompliant with pill-count, did not report noncompliance in MMAS. It was found that these patients either used medicine from their own stock or they lost some tablets and thus reported compliance in the questionnaire. Out of those found not complying with MMAS, 10 patients were found compliant with regard to pill-count. Although they reported missing their prescribed regimen in MMAS questionnaire, but they consumed $>85 \%$ and $<115 \%$ of their prescribed regimen, the range of compliance as per pill-count in our study. In similar study by Lisk et al, out of threepatients who confessed missing therapy, one was satisfactorily compliant as per pillcount. ${ }^{12}$ Similarly, 4 out of 13 patients who reported adequate compliance were found poor compliers after pill-count. ${ }^{12}$

Self-reported questionnaires are known to report overcompliance, as patients tend to respond in a desired way. ${ }^{7}$ MMAS is solely able to identify behavior hurdles to compliance. Pill counts frequently miscalculate compliance, as this method merely uses number of days as denominator in calculating compliance. It usually ignores the chance of having excess medication, especially patients with chronic conditions frequently refill the medication before exhausting it. ${ }^{13}$ Moreover, the cutoff value to differentiate between compliance and noncompliance is arbitrary.

Thus, using MMAS along-with pill-count in assessment of noncompliance increases the efficacy of each tool and complements each other as found in our study. The gold standard method to check compliance still remains therapeutic drug monitoring (TDM) in which plasma trough levels of AED are assessed in patients. However, being an invasive and costly method, TDM can be correlated with pill-count and MMAS.

Limitations of the present study include it being conducted for a shorter duration of 6 months. Thus, pattern and prevalence of long-term compliance with AEDs cannot be evaluated. More number of patients can help to generate more robust data. As sample size in our study was small, it could also have affected the results in our study. The study population in our study mainly hails from urban background, with socioeconomic spectrum being more of lower than upper status. Thus, comparison of patients from different socioeconomic strata could not be done.

\section{Conclusion}

Noncompliance among patients with epilepsy is high and emphasis should be given to educate patients regarding the consequences of missing their therapy. Both MMAS and

Table 2 Pattern of noncompliance among PWE (pill-count and MMAS)

\begin{tabular}{|c|c|c|c|c|c|c|c|}
\hline \multirow[t]{3}{*}{ Tool Used } & & \multicolumn{4}{|c|}{ Pill-count } & \multirow{3}{*}{$\begin{array}{l}\text { Total } \\
n\end{array}$} & \multirow{2}{*}{$\begin{array}{l}p \text {-Value } \\
\text { (Chi-square) }\end{array}$} \\
\hline & \multirow[t]{2}{*}{ Patient } & \multicolumn{2}{|c|}{ Compliant } & \multicolumn{2}{|c|}{ Noncompliant } & & \\
\hline & & $N$ & $\%$ & $n$ & $\%$ & & 0.000 \\
\hline MMAS & Compliant & 31 & 75.6 & $10^{\mathrm{a}}$ & 15.6 & 41 & \\
\hline & Noncompliant & $10^{\mathrm{b}}$ & 24.4 & 54 & 84.4 & 64 & \\
\hline Total & & 41 & 100.0 & 64 & 100.0 & 105 & \\
\hline
\end{tabular}

Abbreviations: MMAS, Morisky medication adherence scale; PWE, patients with epilepsy.

aFour patients lost their medicine, five patients took medicine from their own stock, and one patient took extra medicine after a seizure episode.

${ }^{b}$ All patients have pill-count value $>0.85$ but less than 1.15 , hence classified as compliant but MMAS classified them as noncompliant. 
pill-count are effective tools to identify patients with compliance. Although MMAS is easy to administer, it can unduly report over or undercompliance. Patients can cause pill dumping to become compliant as per pill counting. Pill-count and MMAS, when used in combination, can increase sensitivity to assess compliance in patients with epilepsy. Repeated counselling about importance of compliance is important for patients on AEDs to reinforce the idea ofeffective seizure control.

\section{Funding}

None.

\section{Conflict of Interest}

None declared.

\section{References}

1 Lowenstein DH, Seizures and epilepsy.In: Braunwald E, Fauci AS, Kasper DL, Hauser SL, Jameson JL, Longo DL, et al, eds. Harrison's Principle of Internal Medicine. New York: Mc Graw Hill; 2008 2498-512

2 Lee YK, Ah YM, Choi YJ, Cho YS, Kim KJ, Lee JY. Antiepileptic drug adherence and persistence in children with epilepsy attending a large tertiary care children's hospital. Epileptic Disord 2016;18(4):408-417

3 Jimmy B, Jose J. Patient medication adherence: measures in daily practice. Oman Med J 2011;26(3):155-159
4 Al-Aqeel S, Gershuni O, Al-Sabhan J, Hiligsmann M. Strategies for improving adherence to antiepileptic drug treatment in people with epilepsy. (Review) Cochrane Database Syst Rev 2017;2(2):CD008312

5 Chapman SCE, Horne R, Eade R, Balestrini S, Rush J, Sisodiya SM. Applying a perceptions and practicalities approach to understanding nonadherence to antiepileptic drugs. Epilepsia 2015;56(9):1398-1407

6 Eatock J, Baker GA. Managing patient adherence and quality of life in epilepsy. Neuropsychiatr Dis Treat 2007;3(1):117-131

7 Osterberg L, Blaschke T. Adherence to medication. N Engl J Med 2005;353(5):487-497

8 Mitchell WG, Scheier LM, Baker SA. Adherence to treatment in children with epilepsy: who follows "doctor's orders"? Epilepsia 2000;41(12):1616-1625

9 Gurumurthy R, Chanda K, Sarma G. An evaluation of factors affecting adherence to antiepileptic drugs in patients with epilepsy: a cross-sectional study. Singapore Med J 2017;58(2):98-102

10 Habib M, Khan SU, Hoque A, et al. Antiepileptic drug utilization in Bangladesh: experience from Dhaka Medical College Hospital. BMC Res Notes 2013;6(473):473

11 Johnbull O, Farounb B, Adeleye A, Uche A. Evaluation of factors influencing medication adherence in patients with epilepsy in rural communities of Kaduna State, Nigeria. Neurosci Med 2011;2(4):299-305

12 Lisk DR, Greene SH. Drug compliance and seizure control in epileptic children. Postgrad Med J 1985;61(715):401-405

13 Lam WY, Fresco P. Medication adherence measures: an overview. BioMed Res Int 2015;2015:217047 